\title{
Construction of Environmental Protection Participation Mechanism Under the Background of Governance Modernization
}

\author{
Wu Xi-shuang \\ Law Department of Minjiang University,Fuzhou, Fujian, China \\ 291069132@qq.com
}

Keywords: Governance modernization,Environmental protection participation; Mechanism

\begin{abstract}
In the new ear, to construct an Eco-environmental protection participation mechanism involving multiple entities such as the public, enterprises, and social organizations is a requirement for advancing the modernization of national governance capabilities and governance systems.The thesis starts with the inner relationship between governance modernization and environmental protection participation mechanism. It analyzes the bottleneck constraints in constructing Eco-environmental protection participation system and proposes ways to contrsuct ecological environmental protection mechanisms in the context of governance modernization.
\end{abstract}

\section{治理现代化视域下环保参与机制的构建 \\ 吴喜双 \\ 闽江学院法学院, 福州, 福建, 中国 291069132@qq.com}

关键词：治理现代化；环保参与；机制

中文摘要.新时期，构建公众、企业、社会组织等多元主体共同参与的生态环保参与机制是推 进国家治理能力和治理体系现代化的必然要求。论文从治理现代化与环保参与机制的内在关 系入手, 分析构建生态环保参与机制面临的瓶颈制约, 并提出治理现代化视域下生态环保机 制的构建路径。

\section{1. 引言}

伴随着生态危机的不断加深以及人类生存困境的出现，环境保护应当从 “管理” 转向 “治 理” 这一观念在中国逐渐深入人心，各地都在积极探索通过什么样的机制和路径达成有效的 治理。党的十八届三中全会提出: “全面深化改革的总目标是完善和发展中国特色社会主义 制度, 推进国家治理体系和治理能力现代化。” 环境治理作为国家治理的重要组成部分, 它 应由政府、公众、环保组织等多个主体共同参与、协同互动、民主共治的方式共建环保参与 机制来实现。正如现任北京市市长、前国家环保部部长陈吉宁在十二届全国人大五次会议记 者会上提到的：“环境问题是个公共问题，唯有共治才有共享”。倡导环境治理的公众参与, 实现国家和社会协同共治成为当前全球关注的焦点问题。新形势下，构建一个协调有序、系 统、互动的环保参与机制对于生态危机的缓解以及治理现代化的实现具有重要意义。

\section{2. 治理现代化与环保参与机制的内在耦合}

随着我国环境问题的日益突出以及公众环保诉求的提高，建构环保参与机制势在必行。环 保参与机制是指为了缓解生态危机、实现美丽中国, 公众、法人或社会组织等主体参与环境 管理、监督或执行等活动, 形成合作治理机制。环保参与机制倡导多元主体的多方参与、良 
性互动, 这不仅可以形成污染治理、保护环境的合力, 也是推进国家治理体系和治理能力现 代化的必然选择。治理现代化是指为了实现公共利益, 公众、法人、各级组织等各方主体共 同参与治理, 各治理主体在治理体系中各事其职, 各归其位, 倡导合作共治的局面。治理现 代化是新时期我国深化改革的总目标。党的十八届三中全会通过的《关于全面深化改革若干 问题的决定》指出, 改进社会治理方式, 坚持系统治理, 加强党委领导, 发挥政府主导作用, 鼓励和支持社会各方面参与, 实现政府治理和社会自我调节、居民自治良性互动。在我国推 进社会主义现代化各项事业的进程中, 不可否认，政府是治理的主体，是社会前进的火车头。 然而, 它更离不开社会各主体的协同参与。亨廷顿在论述影响政治发展的相关因素时, 把公 众参与的程度与规模作为衡量一个社会政治现代化的重要尺度。生态环境问题是人类现代化 过程中面临的一项重大挑战, 它具有系统性、长期性和艰巨性等特点。李克强总理在十二届 全国人大五次会议上明确提出, “生态文明是一场蓝天保卫攻坚战、持久战” “打好蓝天保 卫战”, “要求治理环境人人有责, 贵在行动、成在坚持”。治理环境需要多元主体参与, 治理现代化提倡合作共治。因此, 生态环保参与机制的理念与治理现代化的宗旨不谋而合。

\section{3. 新时期构建生态环保参与机制面临的瓶颈制约}

生态环保机制的构建对于改善生态环境、维护生态权益以及推进国家治理现代化具有重要 意义。当前背景下, 我们需要构建一个科学、系统、协调的生态环保机制, 方能有力推动国 家治理现代化进程。这就需要公众的广泛参与、环保组织的配合以及配套法律法规作保障。 然而, 当前我国生态环保机制在公众参与理念、环保组织建设、法律制度等方面有所欠缺, 这极大影响国家治理现代化的推进。

\section{1 治理倡导 “公利” 与公众参与 “私利”之间的冲突}

治理提倡多元主体合作共治, 通过共治促进公共利益实现。俞可平在《国家治理现代化》 一书中指出, 实现国家治理现代化的目标是善治。善治是公共利益最大化过程。它体现为政 府与公民对社会公共事务的协同治理、官民共治。环境保护问题涉及千家万户，与我们息息 相关。公众既是环境污染者, 也是环境保护者。解决环境问题必须依靠公众和各种社会力量 的合作参与。只有公众和社会组织积极参与, 才有可能实现天蓝、水清、地净的美丽中国。 习近平同志在十九大报告指出, 我们要建设的现代化是人与自然和谐共生的现代化。既要创 造更多物质财富和精神财富满足人民日益增长的美好生活需要, 也要提供更多优质生态产品 以满足人民日益增长的优美生态环境需要。公众期待优质的生态产品, 然而面对环境污染和 生态破坏, 公众参与环境治理易受私人利益驱使。利益基于需求和理性的算计, 它是引发人 类行为的重要动机源。马克思曾指出, 人们奋斗所争取的一切, 都与他们的利益有关。在环 境保护中, 公众是否乐于参与环保活动很大程度上取决于行动收益与成本的衡量权衡。当参 与一项环保活动收益大于成本时, 人们更乐于参与环保活动, 否则持冷漠态度。另外, 不同 个人、群体和组织在经济利益和环境利益方面的诉求不同, 这使得公众很难产生联合一致的 行动来维护自身的生态利益。其二, 公共精神不足导致协同度低。公共精神是指以利他方式 关心公共利益的态度和行为方式。发达的公共精神是良好社会治理的决定性因素。公共精神 往往决定公众参与环保的行为状态。然而, 目前我国正处于社会转型期, 公共精神文化缺失、 缺位等导致公众参与环保治理的积极性未能被充分调动, 协同程度低。当前中国特色社会主 义已经进入新时期, 仅仅依靠政府来治理生态环境是无法实现的, 只有调动广大公众参与的 积极性, 构建一个公民、法人和社会组织共同参与的环保机制, 平衡利害关系, 才能最终实 现经济利社会效益和环境效益以及公共利益和个人利益最大化。

\section{2 治理倡导的 “有序参与” 与环保参与的 “无序” 之间的矛盾}

治理现代化包括治理体系现代化和治理能力现代化。良好的治理体系是提升治理能力和推 
动治理现代化的前提和基础。良好的治理体系意味着法治化，即国家的经济生活、政治生活、 文化生活有法可依、依法进行。公众参与环保治理作为国家政治事业的重要组成部分, 也需 要法治保障和依法治理。这需要将生态环保参与作为一项常态化机制规范下来, 从而有助于 实现生态治理现代化。理想状态下，当公众面临环境侵权事件时，他们通过一系列合法途径 或发动社会力量依法参与社会环保组织来维护生态权益。但实践中, 由环境问题引发的、通 过聚集、围堵等方式向有关机关或单位表达意愿、提出要求的环境群体事件频发。如厦门 PX 事件, 浙东海村环境抗争事件。这些事件从一个侧面折射出当前公众参与环保机制存在的弊 端：科学性不足、合理性欠缺、规范性不够。目前为止, 我国已经出台《环保法》、《环境 保护公众参与办法》、《公众环境影响评价法》等法律, 但公众参与环保始终未能尽如人意。 环保法及配套法律法规是公众有序参与生态治理的前提。合理规范公众参与生态治理行为, 使之在法治轨道内进行成为当前我国面临的一项重大课题。目前, 我国环保参与法律机制的 缺失体现在：一是公众参与生态治理权并未受到宪法确认和法律具化。环境权是指公民享有 良好生活环境和合理利用环境资源的权利。将公众的环境权作为宪法认可的权利成为世界上 许多国家的通用做法。但是，我国法律体系中并未对环境权做出具体规定。2018 新修订的宪 法对于 “国务院的职责除了管理国家经济和文化事务，增加了进行生态文明建设的职责” , 而对于公众这个重要主体的参与权未能明确规定。环境权是环境公益诉讼的前提, 宪法上及 相关法律对于公众环境权的法律缺失直接导致现实生活中环境公共利益受到损害时, 公众无 法以环境权受到侵害为由直接行使诉权。二是公众参与生态治理法律系统性不够, 未能形成 完整体系。完整系统的公众参与环境保护制度包括环境信息公开制度、环境立法参与制度、 环境行政参与制度以及环境公益诉讼制度等。这实际上涵盖了公众参与环境保护的范围、程 序、职责、条件等内容, 并且使这些制度形成一个系统机制, 发挥其对公众参与环保的积极 推动作用。但是目前, 我国的环境信息公开制度存在企业信息公开不足、公众参与监督反馈 措施缺失; 公众立法参与制度中典型的 “未端治理” 规定，环保法未能体现包含预防理念的 公众参与环境立法的内容; 环境公益诉讼面临经费和技术难题等问题。良法的缺失阻碍公众 有序参与的通道, 导致他们在维护自身环境权益道理上越行越远, 最终陷入群体性事件争端。

\section{3 环保组织行动 “碎片化”与生态治理 “现代化” 不同步}

非政府组织作为社会力量的重要组成部分, 是推进国家治理现代化的重要主体。社会组织 能力的提升有助于国家治理体系和治理能力的现代化。党的十八届三中全会指出, 发挥政府 主导作用，鼓励和支持社会各方面参与。这意味着社会组织在社会治理中应发挥相应作用。 环保NGO是环境保护公众参与不可或缺的重要力量。近年来, 环保组织在宣传和倡导环境保护、 维护社会和环境权益方面发挥重大作用。然而, 目前我国环保组织面临的问题是: 一是治理 行动体系碎片化。环保NGO组织是以保护环境、优化社会治理格局、实现社会公益为使命的社 会组织, 这决定了环保组织的宗旨和使命是一致的。然而, 现实情况中, 民间环保组织和官 方环保组织资源往往是各自承担服务项目，无法实现相互之间的深度融合、合作与资源共享， 进而导致各环保组织之间协同不足，各自为政。二是政府与公众、组织、企业尚未形成基于 生态治理的利益关联性。目前环保组织分为官方环保组织和民间环保组织。官方环保组织由 于长期依赖于政府组织, 往往以被动参与为主、自主性、独立性差。而民间环保组织参与领 域主要集中于生态公益参与和社区治理, 其参与驱动力主要来自公益价值取向和利益关联度, 因而缺乏长远的动力支持。由于政府在主导生态治理过程中, 对社会环保组织的引导、培育 不足, 造成社会环保组织生态治理能力偏弱, 不能形成有效的协同参与机制, 无法弥补政府 治理的不足。 


\section{4. 治理现代化视域下生态环保机制的构建}

俞可平指出, “治理意味着一系列来自政府, 但又不限于政府的社会公共机构和行为者”。 生态环境问题的最终解决, 离不开一个强有力、并能发挥系统作用的生态环保参与机制, 这 包括生态理念机制, 生态组织机制以及生态法律机制。将三者形成一个有机系统, 使他们相 互协调, 相互作用, 从而形成一个多元主体有效衔接和良性互动的生态环保机制, 发挥其在 治理现代化中的推动作用。

\section{1 以公利促理念之发展, 构建生态理念机制}

生态环境与公众利益息息相关, 然而正如亚里士多德在《政治学》提到的 “凡是属于最 多数人的公共利益常常是最少受人照顾的事务, 人们关怀着自己的所有, 而忽视公共的事务; 对于公共的一切, 他至多只留心到其中对他个人多少有些相关的事务。” 不可否认, 公众参 与生态治理在很大程度上受私人利益驱使。要使公众参与生态治理, 首先应明确影响公众参 与意愿的因素。一般来说, 参与意愿受个人利益关联度的影响。公众参与意愿受几个因素影 响: 一是个人利益关联度。公民有多大动力采取实际行动参与生态治理, 很大程度上取决于 政策的利益相关度。当生态政策能增进公众利益时, 公众就有更大动力支持该项措施; 当某 项生态环保政策损害公众的切身利益, 那么公众则无动力支持该项行动。因此, 这要求政策 在出台生态环保法规或政策时, 应当主动向公众解释生态环保政策与公众利益之间的内在关 系, 从而获得更多的民意支持。二是参与事项难度。生态治理作为一项系统工程, 它需要政 府、专家和公众三者的通力合作方能实现。尤其是政府的顶层设计和专家的技术支持是必不 可少的。普通公众知识水平的缺乏导致无法全面客观评估生态治理措施对政治经济产生的潜 在影响。这就要求政府加大力度向公众解释生态治理方案, 事前通过多种途径解释说明方案 中涉及的数据、术语、和论证过程, 提高公众参与意愿和效率。三是参与效果。公众参与效 果也会影响生态治理中的工作参与。这要求政府机构提高对公众意见的回应力, 对公众意见 是否采纳予以及时反馈并说明理由, 增强公众参与的效能感。环保活动作为一项具有公益价 值的社会活动, 这需要公众参与一种基于共同利益考虑的思维能力。只有当人们意识到, 大 家都能够通过共同行动提升生态环境的整体福利时, 能够通过合作共治改善生态环境时, 公 众参与的行动才能转化为积极、自觉、有效的介入生态管理的活动。

\section{2 以良法促法治之发展, 构建生态法律机制}

实行法治的基本前提是良法。良法是指充分体现公平、正义、平等、民主等基本价值的法 律。要使公众参与在生态环保治理中持续、高效地发挥作用, 使公众参与生态治理成为常态 化机制, 需将公众参与纳入法治化轨道。以法治确认公众参与环保权利、以法治完善参与环 保途径、以法治规范参与秩序。首先, 公众参与环保治理应该得到法律的认可, 使得参与成 为法律权利, 保障公众参与环境治理的参与权。环境治理参与权的首要目标是承认公众参与 的法律地位和构建合理的参与程序。为此, 应以适当方式将公民环境权写入《环境保护法》, 并将其作为一项相对独立的基本权利。并在法律中清晰界定公民环境权的具体内容, 包括环 境使用权、知情权、参与权和请求权等。其次, 构建并形成系统性的公众参与生态治理法律。 为了更好地发挥各参与主体在环境保护中的作用, 需要在相关法律中明确各类主体包括政府、 市场、公众、社会组织等在环境保护国家治理体系中的职责、地位及关系, 政府以什么样的 方式进行引导和干预, 引导和干预的条件、标准、程序、后果等均以立法作出完善的规定。 制定专门的信息公开法, 明确规定信息公开的主体、范围、方式、法律责任和权利救济。建 立一个可有效运转的公众意见表达、收集和反馈系统的公众表达型参与机制。同时, 给予环 保组织公益诉讼主体, 完善环境公益诉讼制度。只有充分发挥各参与主体在治理体系中的积 极能动作用，并以立法形式明确规范各自的职责，才可更好地推进治理现代化。 


\section{3 以培育孵化机制促组织之发展, 构建生态组织机制}

环保社会组织是我国生态文明建设和绿色发展的重要力量, 是环保工作的同盟军、主力 军。生态治理是多元共治而非各自为政, 需要各治理主体之间的协作互动。推进各治理主体 的协作互动, 尤其是适当向市场和社会主体让渡放权, 这是实现治理现代化的重要途径。为 此, 首先必须建立环境保护非政府组织之间的协调机制, 实现不同环保组织间的交流与沟通, 破解彼此间的误会与矛盾, 协调各方立场, 提高环保非政府组织在环境治理与保护中的效率。 其二, 建构科学化机制, 推动环保非政府组织与政府间的互信与有效合作。为更好地实现对 环境问题的有效治理, 环保非政府组织应明确组织定位, 认清使命, 加强自身建设, 通过定 期交流、项目合作等方式加强环保社会组织之间、环保社会组织与其他社会组织、环保社会 组织与媒体之间的合作, 提升政府和公众对环保社会组织的认知和信任, 实现良性互动与有 效合作。

构建环保参与机制是顺应当前生态环境问题日趋恶化、公众环保意识不断觉醒的大趋势， 也是提升国家治理能力的需要。科学、完善的环保参与机制必将极大地推动我国生态文明建 设进程，并能有效提高我国的治理体系和治理能力现代化水平。

\section{References}

[1] Yu Keping,The modernization of state governance, Social Sciences Academic Press, 2015.

[2] Chang Jiwen,Frontier policies and legal problems of ecological civilization, China University of Politiccal Science and Law Press, 2016.

[3] Zhuo Guangjun,The study of public participation system in environment protection, Intellectual Property Publishing House, 2017.

[4] Xiang Junjie.,The research into collaborative governance system of ecological civilization construction in China,China Social Sciences Press, 2016.

[5] Wang Zhenhai,Social organization development and modernization of state governance,People's Publishing House, 2015.

[6] Cao Rongxiang,Ecological governance,Central Compilation and Translation Press, 2015.

[7] Jiang Bixin, Ju Chengwei,Comparative study on the modernization of state governance, China Legal Publishing House, 2016.

[8] Cai Shouqiu.,Law and system of ecological civilization construction, China Legal Publishing House, 2017.

[9] Li Jun. Scientific guide toward new eEra of ecological civilization ,China Renmin University Press, 2015.

[10] Ma Zhenqing,Moral administration and legal management in the modernization of State Governance, China Book Press, 2017.

[11]Yin Shaocheng. Public participation system from the perspective of state governance modernization, vol. 6, pp. 53-56,Social Scientist, 2016

[12]Wang Hongmei, Liu Hongyan,Public participation of our environmental management model construction and practical application, Seeking Truth, vol. 4, pp. 66-71,2016

[13]Wang Jianmin, Legal and moral management combined, Modernization of State Governance Promoted,Contemporary World and Socialism, vol. 1, pp. 166-172,2017.

[14]Chen Runyang, Hua Ming, Zhang Guixiang,Public participation of ecological civilization construction in China, Jiangxi Social Sciences, 2017. 